\title{
Effects of weight training on cognitive functions in elderly with Alzheimer's disease
}

\author{
Thays Martins Vital ${ }^{1}$, Salma S. Soleman Hernández ${ }^{1}$, Renata Valle Pedroso ${ }^{1}$, Camila Vieira Ligo Teixeira ${ }^{1}$, \\ Marcelo Garuffi' ${ }^{1}$ Angelica Miki Stein ${ }^{1}$, José Luiz Riani Costa ${ }^{1}$, Florindo Stella ${ }^{1,2}$
}

\begin{abstract}
Deterioration in cognitive functions is characteristic in Alzheimer's disease (AD) and may be associated with decline in daily living activities with consequent reduced quality of life. Objective: To analyze weight training effects on cognitive functions in elderly with AD. Subjects: 34 elderly with AD were allocated into two groups: Training Group (TG) and Social Gathering Group (SGG). Methods: Global cognitive status was determined using the Mini-Mental State Exam. Specific cognitive functions were measured using the Brief Cognitive Battery, Clock Drawing Test and Verbal Fluency Test. The protocols were performed three times a week, one hour per session. The weight training protocol consisted of three sets of 20 repetitions, with two minutes of rest between sets and exercises. The activities proposed for the SGG were not systematized and aimed at promoting social interaction among patients. The statistical analyses were performed with the $U$ Mann Whitney and Wilcoxon tests for group comparisons. All analyses were considered statistically significant at a $p$-value of 0.05. Results: There were no significant differences associated to the effects of the practice of weight training on cognition in AD patients. Conclusion: In this study, no improvement in cognitive functions was evident in elderly with AD who followed a low intensity resistance exercise protocol. Thus, future studies could evaluate the effect of more intense exercise programs. Key words: cognition, Alzheimer's disease, resistance training.
\end{abstract}

\section{EFEITOS DO TREINAMENTO COM PESOS NAS FUNÇõES COGNITIVAS DE IDOSOS COM DOENÇA DE ALZHEIMER}

RESUMO. A deterioração das funções cognitivas é característica na doença de Alzheimer (DA) e se relaciona com uma pior realização das atividades de vida diária levando a uma pior qualidade de vida. Objetivo: Analisar os efeitos de um programa de treinamento com pesos nas funções cognitivas de idosos com DA. Sujeitos: 34 idosos com DA foram alocados em dois grupos: Grupo Treinamento (GT) e Grupo de Convívio Social (GCS). Métodos: Para caracterização do perfil cognitivo global utilizou-se o Mini-Exame de Estado Mental. Para a mensuração das funções cognitivas foram utilizadas: Bateria Cognitiva Breve, Teste do Desenho do Relógio e teste de Fluência Verbal. Os protocolos oferecidos foram realizados três vezes na semana, durante uma hora. 0 protocolo de treinamento do GT consistiu em realizar três séries de 20 repetições para cada exercício, com dois minutos de intervalo entre séries e entre exercícios. As atividades propostas para o GCS não foram sistematizadas e tiveram por objetivo promover uma socialização dos pacientes. A análise estatística consistiu na utilização dos testes U Mann Whitney e Wilcoxon para comparação intra e entre grupos. Adotou-se nível de significância de $5 \%$ para todas as análises. Resultados: Não foram evidenciadas diferenças significativas relacionadas aos efeitos da prática do treinamento com pesos na cognição de idosos com DA. Conclusão: Neste estudo não houve melhora nas funções cognitivas em idosos com DA que realizaram um protocolo de exercícios resistidos de intensidade leve. Assim, estudos futuros poderiam verificar o efeito de exercícios mais intensos.

Palavras-chave: cognição, doença de Alzheimer, treinamento resistido.

\section{INTRODUCTION}

lzheimer's disease (AD) is characterized
decline resulting from neuronal apoptosis,
predominantly caused by excessive accumula- tion of neurofibrillary tangles and beta-amyloid brain plaques. ${ }^{1-4}$

The key characteristic for clinical diagnosis of $\mathrm{AD}$ is memory impairment and at least one other disorder such as apraxia, agnosia

${ }^{1}$ Institute of Biosciences, Universidade Estadual Paulista (UNESP), Physical Activity and Aging Lab (LAFE), Rio Claro SP, Brazil. ${ }^{2}$ Geriatric Psychiatry Clinic, Universidade Estadual de Campinas (UNICAMP), Campinas SP, Brazil.

Thays Martins Vital. Avenida 24, 1515 - Department of Physical Education / Physical Activity and Aging Lab (LAFE) - 13506-900 Rio Claro SP - Brazil. E-mail: thaysmv@yahoo.com.br 
and aphasia that compromise the professional and social life of the individual. ${ }^{5}$

Changes in cognitive functions, a characteristic of $\mathrm{AD}$, are associated with impairment in instrumental and basic activities of daily living. ${ }^{6,7}$ These modifications can affect the quality of life of patients and caregivers as well as increase the chance of early institutionalization of this patient group..$^{8-11}$

Some studies have shown that physical activity in older adults with $\mathrm{AD}$ can contribute positively by attenuating decline in cognitive function. ${ }^{12-15}$ The possible mechanisms of physical exercise in improving cognition include an increase in cerebral blood flow, generating a greater supply of oxygen and other energy substrates, changes in the synthesis and use of important neurotransmitters for brain activity and also positive interference in brain angiogenesis, synaptogenesis and neurogenesis..$^{14,16-19}$

Most studies involving physical activity and $\mathrm{AD}$ have used general or aerobic training protocols. ${ }^{20-26} \mathrm{Few}$ studies however, have investigated the effects of weight training on cognitive functions in patients with $\mathrm{AD}$.

Studies with cognitively preserved elderly have shown that weight training produces significant gains in cognitive functions..$^{27-30}$

\section{OBJECTIVE}

To analyze the effects of a weight training program on cognitive functions in elderly with Alzheimer's disease.

\section{METHODS}

Subjects. All participants in this study were part of the of Programa de Cinesioterapia Funcional e Cognitiva em idosos com doença de Alzheimer (PRO-CDA), ${ }^{31}$ an extension project offered by the Department of Physical Education, Institute of Biosciences, Universidade Estadual Paulista, Rio Claro campus.

The elderly entered the program through medical indications, and also by their own and/or caregiver's initiative after the announcement of the project in print and broadcast media.

The sample comprised a total of 34 elderly with mildto-moderate stage of disease according to scores on the Clinical Dementia Rating scale. ${ }^{32,33}$

The study inclusion criteria were: clinical diagnosis of $\mathrm{AD}$, according to the criteria of DSM-IV-TR ${ }^{5}$ applied by specialists in the area, and elderly with $\mathrm{AD}$ of mild and moderate severities.

In order to characterize the level of physical activity of the participants, the Modified Baecke Questionnaire for Elderly was applied. ${ }^{34}$
The sample was divided into the two groups by convenience, adopting a similar distribution in terms of age, sex, education and clinical condition (variables characterizing the sample). Thus, the Training Group (TG) consisted of 17 elderly and the Social Gathering Group (SGG) also comprised 17 elderly. The evaluation procedure described below was adopted for both groups.

Caregivers for the elderly signed the consent form, approved along with the research project by the Research Ethics Committee of the Universidade Estadual Paulista, under protocol number 4826.

Evaluation procedures. Firstly, all elderly underwent diagnostic confirmation with a psychiatrist, specialized in Geriatric Psychiatry. After confirming the diagnosis for those patients that met the inclusion criteria of the study, a second evaluation was scheduled with a blinded evaluator.

Subsequently, the first evaluations were scheduled, prior to the familiarization period of this study, in a single visit lasting approximately 1 hour during which the elderly were evaluated using the tests described below. All evaluations were performed during the afternoon in a quiet environment.

The Mini-Mental State Examination (MMSE) was employed to characterize global cognitive status. ${ }^{35}$

As the MMSE is influenced by education, reference values were proposed in order to distinguish subjects with possible cognitive deficits. Brucki et al..$^{36}$ analyzed a Brazilian sample and suggested the following values or studies in this area: illiterates, 20 points; subjects with 1-4 years of schooling, 25 points, 5-8 years, 26,5; 9-11 years, 28 and for individuals with over 11 years of education, 29 points.

The Brief Cognitive Battery $(\mathrm{BCB})^{37,38}$ is a screening instrument that measures cognitive processes, especially memory. This instrument has been used to identify cognitive changes and is divided into domains namely: identification, incidental memory, immediate memory, learning, delayed recall and recognition. Importantly, this instrument is not influenced by education. ${ }^{39}$

This Battery entails presenting the subject with 10 common figures (shoe, spoon, comb, tree, turtle, key, airplane, house, book and bucket). These objects must first be named by the subject (identification/appointment), who are then immediately asked to evoke each item, without having been informed that the objects were to be memorized (incidental memory). In the next stage, the figures are shown again and the subject is required to memorize them (immediate memory), and the procedure is repeated (learning). Again, the figures are 
presented to the subject, with instructions to memorize them and recall them later, after 5 minutes. However, before this evocation, the examiner introduces two tests that serve as distracters: the Verbal Fluency Test and Clock Drawing Test (described below). After these two tests, the subject is asked to evoke the figures previously memorized (5 minutes). Finally, the 10 figures are presented along with 10 others and the participant has to recognize the figures originally presented (recognition). The total score is given as number of successes in each domain, except for the recognition domain in which the number of intrusions (errors) must be subtracted from the number of successes.

The Clock Drawing Test ${ }^{40}$ consists of the task of drawing a clock, inserting pointers and numbers, and setting it to a given hour (e.g. 2:45 a.m.). This test assesses executive functions (planning, abstract thinking, logical and monitoring of executive processing).

The Verbal Fluency test ${ }^{41}$ animals category is a simple test characterized by the ability of the subject to name as many animals as possible within one minute. This test measures processing speed, semantic memory and especially language.

All evaluations described above were applied pre and post intervention.

Design and intervention protocol. The study has a longitudinal design, with an intervention period of 16 weeks. Both intervention protocols involved sessions held three times a week on nonconsecutive days, with each sessions lasting one hour. All elderly had a minimum attendance rate of $70 \%$ in their respective protocols.

Weight training experimental protocol - Training Group (TG). The weight training protocol followed an alternating order of segments, first lower then upper limbs with five exercises performed, always starting with the large muscle groups.

Initially, there was a familiarization period of the patients in the training room (gym) involving three sessions held on nonconsecutive days, during which patients performed one set of 20 repetitions for each exercise, with minimal load. This period preceded the period of the experimental protocol and was not included in the 16 weeks of training.

The exercises selected for the implementation of this protocol were: the Peck Deck, the Pull Down, Leg Press, supported barbell curls performed with free weights and Triceps Pulley. Participants were encouraged to maintain the same movement speed during concentric and eccentric contractions of approximately two seconds. ${ }^{42}$
Warming up - Immediately before the exercise sessions, there was a warm-up comprising a set of 20 repetitions with the minimum load for the respective equipment. These loads were approximately $5 \mathrm{~kg}$ (Peck Deck), 5kg (Pull Down), 7kg (Leg Press), 1kg (Barbell Curls) and $5 \mathrm{~kg}$ (Triceps pulley). ${ }^{42}$

Determining training load and overload - To determine the initial load and subsequent adjustments, a test was performed with two sets of 20 repetitions and a third set until fatigue (participant was instructed to perform as many repetitions as possible), adopting a five-minute interval between attempts. When the last series exceeded 22 repetitions the load was increased. Other parameters such as decrease in speed of execution and voluntary interruption of the movement were used as indicators of fatigue during the determination of load. Both determination and adjustment of loads were performed during the training sessions and were counted in the total volume of training.

The load related to exercising to fatigue in the third set included three sets of 20 repetitions maximum.

Load adjustments were made every 15 days. Adjustment determination was carried out over the course of three sessions, corresponding to one week. Thus, out of the 16 weeks of training, five were dedicated to adjusting load. ${ }^{42}$

Training sessions - Immediately after the tests were conducted to determine or adjust load, training sessions were held, which consisted of performing the same exercises at $85 \%$ of the load established previously in the determination or adjustment for each exercise.

A two-minute interval was allowed between sets and exercises. There was no stretching, before or after the weight training protocol.

For safety, blood pressure was measured before and immediately after the end of each training session, and also medical and pharmacological accompaniment of patients was not interrupted. ${ }^{42}$

Experimental protocol - Social Gathering Group (SGG). The activities proposed for this group were not systematic, however they were designed to promote socialization of patients and adaptation to the routine of the activities developed in the project. The sessions were conducted in a quiet environment without external influence. Activities such as group dynamics, relaxation, short walks, reading, poetry, musical activities, painting, movies, mimes and recreational activities were carried out.

The lessons were developed by a multidisciplinary 
team composed of Physiotherapy, Psychology and Physical Education professionals, as well as undergraduate trainees from the university and other private universities in the city.

For activities and materials, colored pencils and felt pens were used for the drawing and painting activities, rubber balls and balloons for group dynamics, and blunt scissors for cutting out activities. ${ }^{42}$

Statistical analyses. The U Mann Whitney and Wilcoxon tests were used for all variables analyzed: BCB domains (identification, incidental memory, immediate memory, learning, delayed recall and recognition) and distracter tests (Clock Drawing Test and Verbal Fluency). Descriptive statistics were employed to illustrate the data analyzed. The significance level adopted was $5 \%$ for all analyses.

\section{RESULTS}

On the initial analysis, there were no significant differences between groups at pre and post experimental period and likewise no significant differences were found
Table 1. Means and standard deviations of variables characterizing the Training Group (TG) and Social Gathering Group (SGG).

\begin{tabular}{lcc}
\hline & TG & SGG \\
\hline Age (years) & $78.2 \pm 7.3$ & $77.6 \pm 6.5$ \\
\hline Education (years) & $5.4 \pm 3.6$ & $5.2 \pm 3.8$ \\
\hline Mini-Mental State Examination (points) & $18.4 \pm 4.3$ & $17.7 \pm 5.3$ \\
\hline Physical activity level (points) & $5.4 \pm 2.7$ & $3.7 \pm 3.8$ \\
\hline Duration of disease (months) & $31.2 \pm 24.7$ & $32.5 \pm 39.3$ \\
\hline Female & 14 & 13 \\
\hline Male & 3 & 4 \\
\hline
\end{tabular}

for all intra-group variables (domains, Clock Drawing Test, Verbal Fluency and characteristic variables of the sample).

Table 1 shows the characteristics of the study participants.

Tables 2 and 3 contain the descriptive statistics of the data analyzed by domains of the Brief Cognitive Battery (BCB), Clock Drawing Test (CDT) and Verbal Fluency (VF).

Table 2. Medians, range and p-value of domains on BCB for Training Group (TG) and Social Gathering Group (SGG) pre and post intervention.

\begin{tabular}{|c|c|c|c|c|c|c|}
\hline \multirow[b]{3}{*}{ Domains } & & \multicolumn{2}{|c|}{ TG } & \multicolumn{2}{|c|}{ SGG } & \multirow[b]{3}{*}{$\mathrm{p}$} \\
\hline & & \multicolumn{2}{|c|}{ Range } & \multicolumn{2}{|c|}{ Range } & \\
\hline & & Median & Min. - Max. & Median & Min. - Max. & \\
\hline \multirow[t]{2}{*}{ Identification } & Pre & 10.0 & $0-10$ & 10.0 & $3-10$ & 0.7 \\
\hline & Post & 10.0 & $3-10$ & 10.0 & $2-10$ & 0.6 \\
\hline \multirow[t]{2}{*}{ Incidental Memory } & Pre & 2.0 & $0-7$ & 2.0 & $0-9$ & 0.6 \\
\hline & Post & 2.0 & $0-9$ & 3.0 & $0-8$ & 0.9 \\
\hline \multirow[t]{2}{*}{ Immediate Memory } & Pre & 3.0 & $1-9$ & 4.0 & $0-9$ & 0.2 \\
\hline & Post & 5.0 & $0-9$ & 3.0 & $0-10$ & 0.1 \\
\hline \multirow[t]{2}{*}{ Learning } & Pre & 4.0 & $1-8$ & 4.0 & $0-10$ & 0.9 \\
\hline & Post & 5.0 & $0-10$ & 5.0 & $0-8$ & 0.7 \\
\hline \multirow[t]{2}{*}{ Delayed Recall } & Pre & 1.0 & $0-7$ & 0.0 & $0-10$ & 0.6 \\
\hline & Post & 0.0 & $0-10$ & 0.0 & $0-8$ & 0.9 \\
\hline \multirow[t]{2}{*}{ Recognition } & Pre & 4.0 & $0-10$ & 5.0 & $0-10$ & 0.7 \\
\hline & Post & 5.0 & $0-10$ & 5.0 & $1-10$ & 0.4 \\
\hline
\end{tabular}

Table 3. Medians, range and p-value of Clock Drawing Test (CDT) and Verbal Fluency (VF) for Training Group (TG) and Social Gathering Group (SGG) pre and post intervention.

\begin{tabular}{|c|c|c|c|c|c|c|}
\hline \multirow[b]{3}{*}{ Tests } & & \multicolumn{2}{|c|}{ TG } & \multicolumn{2}{|c|}{ SGG } & \multirow[b]{3}{*}{ p } \\
\hline & & \multicolumn{2}{|c|}{ Range } & \multicolumn{2}{|c|}{ Range } & \\
\hline & & Median & Min. - Max. & Median & Min. - Max. & \\
\hline \multirow[t]{2}{*}{ CDT } & Pre & 6.0 & $0-9$ & 4.0 & $0-9$ & 0.4 \\
\hline & Post & 7.0 & $0-9$ & 5.0 & $1-10$ & 0.8 \\
\hline \multirow[t]{2}{*}{ VF } & Pre & 5.0 & $3-13$ & 6.0 & $1-11$ & 0.9 \\
\hline & Post & 6.0 & $0-12$ & 5.0 & $0-13$ & 0.6 \\
\hline
\end{tabular}




\section{DISCUSSION}

The present study found no significant differences associated to the effects of the practice of strength training on memory and cognition in elderly with $\mathrm{AD}$.

By contrast, some studies have found positive effects of physical activity on cognitive function in elderly with AD. ${ }^{12-15}$

Antunes et al. ${ }^{16}$ emphasized that the effects of the practice of physical activity depend on the cognitive task and type of exercise chosen.

All studies reviewed by Coelho et al. ${ }^{15}$ involved protocols of generalized physical activity or aerobic training. Few studies have addressed cognitive function in elderly and weight training ${ }^{43}$ while fewer still have investigated the effects of such training on cognitive functions in elderly with $\mathrm{AD}$.

Perrig-Chiello et al. ${ }^{27}$ and Lanchman et al..$^{44}$ found no significant differences in memory in the elderly after practicing resistance training.

However, Cassilhas et al. ${ }^{29}$ and Liu-ambrose et al. ${ }^{45}$ showed positive effects of weight training on memory and cognitive functioning among elderly. Busse et al. ${ }^{30}$ found that older adults with memory impairment had significant improvement on tests of episodic memory after undergoing a period of resistance training.

It is important to emphasize that none of the studies mentioned above involved a sample of elderly with $\mathrm{AD}$.

Thomas and Hageman ${ }^{46}$ found positive effects of weight training on neuromuscular function of elderly with dementia, however, the sample was heterogeneous in type of dementia and authors did not focus on the results for cognition of participants.

A review by Hurley et al. ${ }^{47}$ found an inverse relationship between muscle strength and AD. The systematic review conducted by Coelho et al. ${ }^{15}$ found that systematic physical activity can preserve or even improve cognitive function in elderly with $\mathrm{AD}$.

Given the fact that the present study failed to show improvement in any of the cognitive variables tested, we suggest the implementation of resistance training with higher intensities, in order to verify whether greater intensities promote gains in cognitive levels.

This finding however, must be treated with caution since progression of cognitive decline is also related to stage of the disease. Thus, not only the protocols used but the clinical condition of elderly, still relatively preserved, could have influenced the study results.

The number of sessions in the present study may have been insufficient to generate significant results, because there were only 48 sessions of weight training, of which 15 were used to adjust the load.
Lachman et al. ${ }^{44}$ found that elderly people who had greater changes in load during the training program showed significant improvement in working memory. In the present study, the evolution of load achieved by all patients in the TG was observed, and the training volume was expressed by multiplying the number of sets (three sets) by the number of repetitions (20 repetitions) by the average load of all patients for each exercise.

For all periods employed, the patients showed an increase of at least $50 \%$ in the total volume of exercise. However, no significant difference in memory as assessed by the BCB was detected. Therefore, we emphasize that the number of repetitions used in this study may not have generated sufficient intensity to promote significant responses, mainly in the central levels, whereas the intensity of the present training was considered low.

First, it is important to emphasize that this low intensity of training was determined to promote greater patient safety, thus avoiding possible muscle damage.

The training protocol used in this study seems to have generated an intensity which was not sufficient to generate a satisfactory response among patients, thus being considered an exercise program of low intensity. Programs investigating higher intensities in training have tended to show different results regarding the effects of weight training and cognitive functions in elderly with $\mathrm{AD}$.

Moreover, no significant difference was observed in the groups' behavior after the intervention period on the distracter tests: CDT and VF aimed at testing frontal executive functions and language.

Adherence to physical activity programs by elderly with $\mathrm{AD}$ remains a limitation to the research on this population. In our study, the program was widely publicized in newspapers and television and medical indications also helped patients enter the program. However, factors such as the association of $\mathrm{AD}$ with a clinical pathology and resistance or lack of availability of caregivers, represent barriers to the practice of physical activity by this population.

Motivation to attend the program should be constant, since it is an inherently unstable population from a behavioral point of view. In this sense, inter and intra generations should be encouraged in order to strengthen social networks. Thus, it is believed that investigation into barriers to the practice of physical activity in this population may yield further insights for future approaches.

The present study has some limitations such as the absence of a control group that did not do any kind of 
activity, the non-random distribution, and also the small sample size.

Accordingly, it is important to encourage further studies that investigate and manipulate the frequency, number of sets, repetitions, interval and intensity of training in order to verify other responses to resistance training in elderly with AD. Furthermore, the use of other instruments to determine cognitive functions in more depth could help to investigate the results of the training. Studies should be undertaken to verify the effects of this type of training on motor functionality of $\mathrm{AD}$ patients and also to ascertain how this type of training could help reduce the burden and stress of caregivers.

Acknowledgments. LAFE - Laboratório de Atividade Física e Envelhecimento, Instituto de Biociências, Departamento de Educação Física, Unesp/Rio Claro. PRO-CDA - Programa de Cinesioterapia Funcional e Cognitiva em idosos com doença de Alzheimer, Instituto de Biociências, Departamento de Educação Física, Unesp/Rio Claro. Cnpq - Conselho Nacional de Desenvolvimento Científico e Tecnológico. CAPES - Coordenação de Aperfeiçoamento de Pessoal de Nível Superior

\section{REFERENCES}

1. Braak E, Griffing K, Arai K, et al. Neuropathology of Alzheimer's disease: what is new since A. Alzheimer? Eur Arch Psychiatry Clin Neurosci 1999;49:14-22

2. Braak H, Braak E. Neuroanatomy of Alzheimer's desease. Alzheimer's Res 1997;3:235-247.

3. Braak H, Braak E. Evolution of neuronal changes in the course of Alzheimer's disease. J Neural Transm 1998;53:127-140.

4. Swerdlow RH. Is aging part of Alzheimer's disease, or is Alzheimer's disease part of aging? Neurobiol Aging 2007;28:1465-1480.

5. American Psychiatric Association (APA). Diagnostic and Statistical Manual of Mental Disorders. 4th ed, Text Revision (DSM-IV-TR). Washington: DC; 2000:943.

6. Perry RJ, Hodges JR. Relationship between functional and neuropsychological performance in early Alzheimer disease. Alzheimer Dis Assoc Disord 2000;14:1-10

7. Aguero-Torres H, Fratiglioni I, Guo Z, et al. Dementia is the major cause of functional dependence in the elderly: 3-year follow-up data from a population based study. Am J Public Health 1998;88:1452-1456.

8. Nitrini R, Caramelli P, Mansur L, Neuropsicologia: das bases anatômicas à reabilitação. São Paulo: HCFMUSP; 2003.

9. Andersen CK, Wittup-Jensen KU, Lolk A, et al. Ability to perform activities of daily living is the main factor affecting quality of life in patients with dementia. Health Qual Life Outcomes 2004;2:52.

10. Senanarong V, Poungvarin N, Jamjumras $P$, et al. Neuropsychiatric symptoms, functional impairment and executive ability in Thai patients with Alzheimer's Disease. Int Psychogeriatr 2005;1:81-90.

11. Lanari A, Amenta F, Sivestrelli G, et al. Neurotransmitter déficits in behavioural and psychological symptoms of Alzheimer's disease. Mech Ageing Dev 2007;127:158-165

12. Heyn P. The effect of a multisensory exercise program on engagement, behavior, and selected physiological. Am J Alzheimer's Dis Other Demen 2003; 18:247-251.

13. Liu-Ambrose T, Donaldson MG. Exercise and cognition in older adults: is there a role for resistance training programmes? $\mathrm{Br} \mathrm{J}$ Sports Med 2009:43:25-27.

14. Deslandes A, Moraes H, Ferreira C, et al. Exercise and Mental Health: Many Reasons to Move. Neurophycobiology 2009;59:191-198.

15. Coelho FGM, Santos-Galduroz RF, Gobbi S, Stella F. Atividade física sistematizada e desempenho cognitivo em idosos com demência de Alzheimer: uma revisão sistematizada. Rev Bras Psiquiatr 2009;31: 163-170.

16. Antunes HKM, Santos RF, Cassilhas R, et al. Exercício físico e função cognitiva: uma revisão. Rev Brás Med Esporte 2006;12:108-114.

17. Larson, EB, Wang I, Bowen J, et al. Exercise is associated with reduced risk for incident dementia among persons 65 years of age and older. Ann Int Med 2006;144:73-81.

18. Kashihara K, Maruyama T, Murota M, Nakahara Y. Positive Effects of Acute and Moderate Physical Exercise on Cognitive Function. J Physiol Anthropol 2009;28:155-164.

19. Lista I, Sorrentino G. Biological mechanisms of physical activity in preventing cognitive decline. Cell Mol Neurobiol 2009;30:493-503.

20. Hernandez SSS, Coelho FGM, Gobbi S, Stella, F. Efeitos de um pro- grama de atividade física nas funções cognitivas, equilíbrio e risco de quedas em idosos com demência de Alzheimer. Rev Bras Fisiot 2010;14:68-74.

21. Teri L, Gibbons LE, Mccurry SM, et al. Exercise plus behavioral management in patients with Alzheimer disease: a randomized controlled trial. J Am Med Assoc 2003;290:2015-2022.

22. Rolland Y, Pillard F, Klapouszczak A, et al. Exercise Program for Nursing Home Residents with Alzheimer's Disease: A 1-Year Randomized, Controlled Trial. J Am Geriatrics Soc 2007;55:158-165.

23. Arkin S. Student-led exercise sessions yield significant fitness gains for Alzheimer's patients. Am J Alzheimer's Dis Other Demen 2003;18: 159-170.

24. Aman E, Thomas DR. Supervised Exercise to Reduce Agitation in Severely Cognitively Impaired Persons. J Am Med Dir Assoc 2009;10: 271-276.

25. Steinberg M, Leoutsakos JS, Podewils LJ, Lyketsos CG. Evaluation of a home-based exercise program in the treatment of Alzheimer's disease: The Maximizing Independence in Dementia (MIND) study. Int J Geriatr Psychiatry 2009;24:680-685.

26. Arcoverde C, Deslandes A, Rangel A, et al. Role of physical activity on the maintenance of cognition and activities of daily living in elderly with Alzheimer's disease. Arq Neuropsiquiatr 2008;66:323-327.

27. Perrig-Chiello P, Perrig WJ, Ehrsam R, Staehelin HB, Krings F. The effects of resistance training on well-being and memory in elderly volunteers. Age Ageing 1998;27:469-475.

28. Özkaya GY, Aydin H, Toraman FN, Kizilay F, Ozdemir O, Cetinkaya V. Effect of strength and endurance training on cognition in older people. J Sports Sci Med 2005;4:300-313.

29. Cassilhas RC, Viana VA, Grassmann V, et al. The Impact $f$ Resistance Exercise on the Cognitive Function of the Elderly. Med Sci Sport Exerc 2007;39:1401-1407.

30. Busse AL, Jacob-Filho W, Magaldi RM, et al. Effects of Resistance Training Exercise on Cognitive Performance in Elderly Individuals with Memory Impairment: Results of a Controlled Trial. Einstein 2008;6: 402-407.

31. Garuffi M, Gobbi S, Hernandez SSS, et al. Atividade física para promoção da saúde de idosos com doença de Alzheimer e seus cuidadores. Rev Bras Ativ Fís Saúde 2011;16:80-83.

32. Morris J. The Clinical Dementia Rating (CDR): current version and scoring rules. Neurology 1993;43:2412-2414.

33. Montaño MBMM, Ramos LR. Validade da versão em português da Clinical Dementia Rating (CDR). Rev Saúde Pública 2005;39:912-917.

34. Voorrips L, Ravelli A, Dongelmans P, Deurenberg P, Van Staveren W. A physical activity questionnaire for elderly. Med Sci Sports Exerc 1991;23: 974-979.

35. Folstein MF, Folstein SE, Mchugh PR. Mini-mental state. A practical method for grading the cognitive patients for the clinician. J Psychiatry Res 1975;12:189-198.

36. Brucki SMD, Nitrini R, Caramelli P, Bertolucci PHF, Okamoto JH. Suggestions for the utilization of the mini-mental state examination in Brazil. Arq Neuropsiquiatr 2003;61:777-781.

37. Nitrini R, Lefèvre BH, Mathias SC, et al. Testes neuropsicológicos de 
aplicação simples para o diagnóstico de demências. Arq Neuropsiquiatr 1994; 52:457-465.

38. Nitrini R, Caramelli P, Porto CS, et al. Brief cognitive battery in the diagnosis of mild Alzheimer's disease in subjects with medium and high levels of education. Dement Neuropsychol 2007;1:32-36.

39. Christofoletti G, Oliani MM, Stella F, Gobbi S, Gobbi LTB. Influence of scholarity on cognitive screening test in elderly people. Dement Neuropsychol 2007;1:46-51.

40. Sunderland T, Hill JL, Mellow AM, et al. Clock drawing in Alzheimer's disease. A novel measure of dementia severity. J Am Geriatrics Soci 1989;37:725-729.

41. Lezak MD. Neuropsychological Assessment. $3^{\circ}$ ed. New Yourk: Oxford Press; 1995.

42. Garuffi M, Costa JLR, Hernández SSS, et al. Effects of resistance training on the performance of activities of daily living in patients with Alzheimer's disease. Geriatrics and Gerontology International 2012;
Disponível em: 10.1111/j.1447-0594.2012.00899.x. Acesso em 25 de junho de 2012.

43. Busse AL, Gil G, Santarém JM, Filho WJ. Physical activity and cognition in the elderly. Dement Neuropsychol 2009;3:204-208.

44. Lachman ME, Neupert SD, Bertrand R, Jette AM. The effects of strength training on memory in older adults. J Aging Physl Act 2006;14:59-73.

45. Liu-Ambrose T, Donaldson MG, Ahamed Y, et al. Otago home-based strength and balance retraining improves executive functioning in older fallers: a randomized controlled trial. J Am Geriatr Soc 2008;56: 821-830.

46. Thomas VS, Hageman PA. Can neuromuscular strength and function in people with dementia be rehabilitated using resistance-exercise training? Results from a preliminary intervention study. J Gerontol Med Sci 2003; 58A:746-751.

47. Hurley BF, Hanson ED, Sheaff AK. Strength training as a countermeasure to aging muscle and chronic disease. Sports Med 2011;41:289-306. 